\title{
EDUCATION IN ROMANIA IN THE SARS-CoV-2 PANDEMIC
}

\author{
Paraschiva Cherecheș-Panța \\ "Iuliu Hațieganu" University of Medicine and Pharmacy Cluj-Napoca
}

\begin{abstract}
The pandemic which lead to school closure as a part of isolation strategies of potential infection sources may result in damage to children's social, psychological, and educational development. Reopening schools on the other hand must be based on understanding the epidemiological risk and on the application of prophylaxis measures.

Key words: education, SARS-CoV-2 pandemic

The year 2020 marked a paradigm shift that affected society as a whole. The onset of a pandemic with a new strain of coronavirus that causes a severe acute respiratory syndrome (SARS-CoV2) is the direct leading cause. Regardless of social status, age, urban or rural residence, or profession, we have all been exposed to changes in behavior, attitude but also in thinking and in feelings. Adaptation possibilities vary depending on a multitude of factors. The closure of schools and kindergartens has had and still has a major impact on everyone's life.

There is no consensus on the usefulness of the measure of closing educational institutions. In the present material we tried to bring arguments for and against this method of social isolation. Health policies differ from country to country, with the socio-economical level of the country being one of the variables that correlate with some of the measures applied to online education or physical presence in school [1].
\end{abstract}

Some countries such as Iceland, Sweden or Taiwan have never closed primary schools. In Germany, France, Denmark, Finland or Norway it is recommended to reopen schools.

There are several aspects under which this issue can be addressed.

\section{Susceptibility to SARS-CoV2 infection among students}

In children, studies have shown that regardless of the extent of clinical manifestations, the viral load is similar to that of adults. However, the risk of children transmitting the disease is low.

From the reports of currently available epidemiological observations, children and adolescents are up to half as likely to develop severe forms of the disease.

The clinical picture of COVID-19 in children is generally dominated by manifestations of low severity: cough, low-grade fever, respiratory discomfort, anosmia or olfactory disorders, sometimes non-specific cutaneous and digestive manifestations. The proportion of cases in which the manifestations are severe, with signs of respiratory failure, is much lower compared to adult patients [2]. However, severe cases have been reported in $4.2 \%$ of children aged $6-10$ years, in $4.1 \%$ in the age group $11-15$ years and in 3\% of those over 15 years of age.

\footnotetext{
* Correspondent author: Paraschiva Cherecheș-Panța, "Iuliu Hațieganu” University of Medicine and Pharmacy Cluj-Napoca, e-mail: pusacherechespanta@gmail.com Article received: 9.12.2020, accepted: 21.12.2020, published: 10.01.2021

Citation: Cherecheș-Panța P. Journal of School and University Medicine 2020;7(4):5-9
} 


\section{The risk of students transmitting COVID-19 to adults or their peers}

Previous epidemics with viruses such as the 2009 H1N1 flu raised important concerns seeing that at that time children were an important transmission factor. However, studies published after the first months of the 2020 pandemic have shown a relatively low role of children in virus transmission, including SARS-CoV2 $[3,4]$. The data were also analyzed in comparison with the previous coronavirus epidemic, in which it was found that students are a modest vector of infection spread compared to other age groups.

The possibility of transmission exists but is low, especially in young children [1,4]. A situation of outbreaks was reported in adolescents in a high school in northern France [5] in which high transmission rates between students and teachers was found (38\% for colleagues and $49 \%$ for teachers, respectively), but with a rate of intra-family transmission, to parents and siblings, significantly lower (10-11\%).

A study published in August 2020 analyzed how the first children became infected in Switzerland [6]. The authors found that the outbreaks' point of origin was not the school, but rather there were clusters of infection within the family, with one of the adults being the first symptomatic member of the family suspected or confirmed with COVID-19. Child-to-child or child-to-adult transmission was not confirmed in the 4310 patients included in the study. Moreover, in a third of the families that were analyzed, although the parents were positive, the children had no symptoms and were not infected [6]. The transmission of the infection from child to adult could not be specified in any of the cases studied.

\section{The advantages of reopening the schools}

The European Union strongly recommends the reopening of schools, but emphasizes the importance of two aspects: on one hand the ability to apply distancing measures in schools and on the other hand the emergence of arguments of the stationary or downward trend of the epidemiological risk [7]. In other words, if there is a decrease in the number of cases in a significant period of time (minimum 2 weeks, optimal 4 weeks) it is recommended for children to return to school.

\section{The disadvantages of online education}

The quality of distance learning is reduced due to many factors:

- the child's attention, regardless of age and level of education (primary school, secondary school, college or university) cannot be captured to the same extent in distance learning as in classic classroom teaching,

- lack of exercise, of physical activity, even lack of walking, movement to and from school have a major impact on physical and mental health,

- the child's posture in front of the screen is in most cases an inadequate one, which can lead to disorders of the spine,

- the child's mental health may be affected on one hand by social isolation but also by reduced school support, on the other hand,

- in some families children who stay at home constantly have a higher risk of being exposed to domestic violence,

- children from disadvantaged backgrounds are deprived, due to the lack of school attendance, of a breakfast that was offered through the national program introduced in recent years,

- the teachers are not fully prepared to carry out their online education activity, do not have a system for structuring the educational material in a standardized and unitary methodology, nor can they be verified on the quality (even the quantity) of information provided to students,

- logistically, neither teachers nor students were prepared for online education, not even in the short term, much less in the long term,

- the inequality between the different social classes is accentuated if we are to refer to the availability of electronic hardware supports (tablets, computers, laptops, etc.), the quality of the internet connection and the access to the online activity platforms. 
We must not omit the implications of parental absenteeism from work when the pupil is young and unable to access the online teaching platforms independently.

\section{Stages of reopening schools}

The control of the spread of SARS-CoV2 infection is fundamentally based on the testing capacity, for active and rapid detection of new cases, and on the ability to monitor and isolate them.

The decision to reopen educational units must be made in a personalized way, based on the situation of each region concerned.

A first step in this direction should be the reopening of kindergartens and primary schools. Social isolation and distancing of children from these age groups, under 9-10 years, is illusory. Also, the risk of these children transmitting the disease to the educators or teachers is minor. The teacher could constantly wear a transparent mask that psychologically brings children closer to him while also protecting those who cannot wear a mask from the risk of being infected by a teacher. Children, especially young preschoolers and primary school children, learn not only math, Romanian and foreign languages, but also how to interact with other children of the same age and obey the rules imposed by the teacher, or by social norms. Harmonizing behavior in the community is invaluable and cannot be done online.

The second stage would be the opening of all schools for all levels of education.

Between September and December 2020, each educational institution should have structured both its premises and its curriculum and staff so that it could reopen its doors for students.

Means of protection, such as the availability of soap, running hot water or paper towels, are mandatory regardless of the location of the school. Auxiliary staff should be very well represented, so that the sanitation and disinfection of each educational space and especially of the common areas is carried out several times during the day. The habit of frequently ventilating the classroom, regardless of outside temperatures, must be a constant practice.

The reopening of schools also involves transporting students to and from school. The means of transportation must be doubled in number and, as far as possible, there must be buses dedicated exclusively to transporting students.

At the current national rate of infection only in numerically small communities is possible to have constant school education. In large cities and crowded schools, the measure of hybrid education must be applied, in which only half of the class, a maximum of 12-15 students, attend school while the other half is present online, alternating weekly study groups in each class.

The teaching materials (books) could be kept in the classroom and the student should write down only the homework, without taking home unnecessary, possibly contaminated, equipment.

One aspect of prophylaxis would be the social distancing of teaching and auxiliary staff outside teaching hours, especially in the common areas.

Returning to classical education is essential to prevent what UNICEF has called: "a catastrophe for humanity" [8].

In August 2020 a group of UK researchers tried to imagine a model for optimizing the reopening of schools so that the second wave of the pandemic would be minimized [9]. Their conclusion was that the best strategy is to increase the testing capacity using the RT-PCR test method for SARS-CoV-2 and to isolate the confirmed cases.

\section{Infection prophylaxis in students with risk factors}

There are students with chronic conditions who have an increased risk for infection while also having an increased risk for severe evolution of any acute infection. For these students, online education could be a better alternative during this pandemic. However, the strategy applied in these situations must be personalized, depending on the individual circumstances:

- ease of access to online education, 
- the quality of the curriculum in the institution attended by the student,

- the parent's willingness to be with the student at all times,

- the possibility of following with maximum rigor the means of hygiene and individual protection in the educational unit.

The balance between the advantages and disadvantages of online education will be analyzed by parents together with the family doctor, the pediatrician who monitors the patient and the student's teachers.

From the categories of patients with risk factors, a first mention should be made for students with acquired or congenital immunosuppressive diseases for which online education would be an optimal alternative today. Other categories of patients are:

- children with autoimmune diseases (juvenile idiopathic arthritis, systemic lupus erythematosus, autoimmune hepatitis, autoimmune haemolytic anemia, thrombocytopenic purpura, etc.), especially if the daily therapy consists of glucocorticoids, immunosuppressants or antibiotic therapy),

- severe allergic asthma with biologic therapy (omalizumab),

- congenital heart malformations,

- genetic diseases at risk for infections,

- cystic fibrosis or bronchopulmonary dysplasia.

\section{Decalogue of non-specific prophylaxis methods recommended in schools}

1. Wearing a mask

2. Washing hands frequently with warm water and soap.
3. Frequent ventilation of rooms: for classrooms ventilation must be carried out for at least 5 minutes every 45-50 minutes.

4. Disinfectant solutions cannot replace hand washing

5. All students and preschoolers are to receive vitamin D3 in doses between 800-1000 IU / day, daily, between September and April, annually.

6. Proper, balanced diet, including at least a daily portion of fresh fruit and / or freshly squeezed fruit juices

7. Influenza vaccination is effective in stimulating immunity. Both the injectable and the topical nasal preparation can be given to children. Children younger than 9 years who receive their first flu vaccine, will receive two doses, the second one at least four weeks after the first one. For the other categories, only one dose of influenza vaccine will be administered each year.

8. Anticoronavirus vaccination, which is becoming a topical issue, cannot be discussed for children as a prophylactic strategy at this moment. Studies will be able to support the efficiency and safety of vaccination in the second half of 2021 for children, initially in adolescents, children over 12 years and only at a later stage, in late 2021 or even later, in children in primary school or kindergarten.

9. Sanitation of toilets and the provision of paper towels, used for drying hands, must be carried out during each break.

10. Sanitation of classrooms, of all surfaces (handles, benches, blackboard, etc.) must be performed daily at the end of the classes. 


\section{References}

1. Viner RM, Bonell C, Drake L, et al. Reopening schools during the COVID-19 pandemic: governments must balance the uncertainty and risks of reopening schools against the clear harms associated with prolonged closure. Arch Dis Child Month 2020 Vol 0 No 0.

2. Xia W, Shao J, Guo Y, et al. Clinical and CT features in pediatric patients with COVID-19 infection: Different pointsfrom adults. Pediatr Pulmonol. 2020;55:1169-1174. https://onlinelibrary.wiley.com/doi/full/10.1002/ppul.24718.

3.Viner RM, Russell SJ, Croker H, et al. School closure and management practices during coronavirusoutbreaks including COVID-19: a rapid systematic review. Lancet Child Adolesc Health 2020;4:397-404.

4. Davies NG, Klepac P, Liu Y, et al. Age-Dependent effects in the transmission and control of COVID-19 epidemics. Nat Med 2020. doi:10.1038/s41591-020-0962-9.

5. Fontanet A, Tondeur L, Madec Y, et al. Cluster of COVID-19 in northern France: A retrospective cohort study. medRxiv 2020; published onlineApril 23. https://doi. org/10.1101/2020.04.18.20071134

6. Posfay-Barbe KM, Wagner N, Gauthey M, et al. COVID-19 in Children and the Dynamics of Infection in Families. Pediatrics. 2020;146(2): e20201576

7. UNESCO. Education: From disruption to recovery. 2020. https://en.unesco. org/covid19/educationresponse (accessed July 25, 2020)

2 Royal Society DELVE Initiative. Balancing the risks of pupils returning to schools. 2020. https://rs-elve.github.io/ reports/2020/07/24/balancingthe-risk-of-pupils-returning-toschools. html (accessed July 25, 2020).

8. United Nations. Policy brief: the impact of Covid-19 on children, 2020.

9.Panovska-Griffiths J, Kerr CC, Stuart RM, Mistry D et al .Determining the optimal strategy for reopening schools, the impact of test and trace interventions, and the risk of occurrence of a second COVID-19 epidemic wave in the UK: a modelling study. Lancet Child Adolesc Health 2020 https://doi.org/10.1016/ S2352-4642(20)30250-9 